\title{
Does Conflict Content Affect Learning from Simulations? A Cross-National Inquiry into the Israeli-Palestinian and Guatemalan Conflict Scenarios
}

\author{
C. Esra Cuhadar ${ }^{1}$ and Ronit Kampf ${ }^{2}$ \\ 1 Department of Political Science and Public Administration, Bilkent University, Ankara, Turkey \\ 2 Department of Communications, Tel Aviv University, Tel Aviv, Israel
}

\section{Keywords}

experimental research, identity, computer games, negotiation simulation.

\section{Correspondence}

C. Esra Cuhadar, Political

Science, Bilkent University,

Ankara 06800, Turkey; e-mail:

esracg@bilkent.edu.tr.

\begin{abstract}
It is important to find out whether the content of a simulation has any effect on learning, whether students learn better when the simulation is about a conflict they directly experience as opposed to a conflict they have hardly heard about, and whether learning about a specific conflict changes from one identity group to another. In this article, we address these questions in a five-group experimental study, with direct parties to the conflict (Israeli-Jewish, Palestinian, and Guatemalan), third/secondary parties to the conflict (Turkish, American, and Brazilian), and distant parties to the conflict. Our results indicate that learning varies not only from one group to the other, but also with the salience of the conflict. While the simulations increase the level of knowledge about that particular conflict in almost all situations, when attitude change is concerned, the effects diversify from one group to the other.
\end{abstract}

One who is far from my eye is also far from my heart.

Gözden ırak, gönülden de irak. ..An old Turkish proverb

Simulations and role-plays are used frequently in the teaching of conflict analysis and resolution. In traditional simulations, students act out a specific conflict or negotiation scenario delivered by the instructor. Especially in the last decade, role-playing has been subject to criticism by researchers and instructors on several grounds. Following these criticisms, which called for assessing commonsense assumptions about conflict and negotiation teaching, scholars assessed the effectiveness of simulations in teaching conflict and negotiation. Despite the growing number of studies inquiring about the effectiveness of simulations, several issues are still relatively untouched. For instance, we know very little about the effect of computer-based simulations, especially the effects of peace games. The literature emphasizing the negative effects of violent war games is abundant, yet there is little research on the effects of peace games and whether they increase the players' ability to empathize with the other or their willingness to negotiate and problem solve.

We also know little about the effectiveness of simulations in different cultural contexts and whether different cultural groups relate to the same content in a similar way or not. Education scholars argue that the context in which learning takes place matters. So, does the content of simulation have any effect on learning? Do students learn better if the simulation is about a conflict they directly or personally have 
experienced as opposed to a conflict they have hardly heard about? Does learning from simulations change from one identity group to another?

In this article, we tackle these questions. We inquire about the effectiveness of a computer-based peace game, called Global Conflicts, which simulates two different conflict scenarios, to see whether this game enhances learning and perspective taking, and whether this learning varies with the content of the conflict or not. We also inquire whether learning about conflicts changes from one context to another by having students belonging to different national identity groups play the same conflict scenario. In this study, we measured learning about conflicts in two areas: (a) to what extent the participants' knowledge about the conflict changed, and (b) whether the participants' attitudes toward the conflict has changed or not (i.e., perspective taking ability).

We found that acquaintance with the conflict, geographic proximity, and emotional closeness to a specific conflict narrative make a difference in the learning outcome and the ability to take the perspective of the other parties in the conflict. Whether the conflict is a globally salient one, like the IsraeliPalestinian conflict, or a less known one, like the Guatemalan civil war, influences the outcome of learning as well as the nature of the conflict narrative. In addition, the nature of the group receiving the information also influences the outcome. Learning outcomes vary with different audiences playing the game, that is, whether the parties are direct parties to that conflict, third parties, or distant parties.

\section{Using Computer Games in Teaching About Conflicts}

Teaching in the conflict analysis and resolution field relies heavily on simulations and games (Brown et al., 2003; Druckman, 2011; Druckman \& Ebner, 2008, 2013; Movius, 2008; Wilkenfeld, Young, Queen, \& Assal, 2005). Despite its extensive use, the effectiveness of role-plays and simulations has only recently been assessed in a systematic manner (Brown et al., 2003; Druckman \& Ebner, 2008, 2013; Loewenstein \& Thompson, 2000; Movius, 2008; Torney-Purta, 1998). Yet, these studies offer some conflicting results. For instance, research with ICONS and GlobalEd has argued that simulations are more effective for acquiring knowledge about conflicts compared to traditional lectures because they are more successful in raising interest and motivation among students (see Torney-Purta, 1998; Wilkenfeld et al., 2005, for ICONS; see Gehlbach et al., 2008, for GlobalEd). On the other hand, Druckman and Ebner $(2008,2013)$ have suggested that role-plays motivate learning when students are passive, but otherwise they are not necessarily more effective than learning through lectures and case studies. In fact, Druckman and Ebner (2013) have shown that simulations may enhance learning if students design the simulations rather than participating in them as role players. Nevertheless, there seems to be consensus that simulations and games are effective, because they manage to raise student motivation and interest.

The use of simulations has been criticized on several grounds though (e.g., Lewicki, 2000; Movius, 2008). The first line of criticism argued that role-playing in simulations elicits cultural stereotypes (Kersten, Koszegi, \& Vetschera, 2003). The second major criticism suggested that simulations put students in artificial situations, which has no relevance to real life and misses the complexity of a conflict setting (Honeyman, Coben, \& De Palo, 2009; Volkema, 2007). Role-plays isolate students from a meaningful context that they can relate to personally (Alexander \& LeBaron, 2009). Finally, role-plays and simulations are criticized for having little or no transference of skills to real-life settings (Alexander \& LeBaron, 2009; Loewenstein \& Thompson, 2000; Movius, 2008; Nadler, Thompson, \& Boven, 2003).

Several studies have been undertaken to specifically address these criticisms. For instance, Druckman and Ebner (2013), Ebner and Efron (2005), Honeyman et al. (2009), Honeyman, Coben, and De Palo (2010), and Volkema (2007) introduced different types of real-life stakes to the simulation environment. Druckman and Ebner (2013) asked students to write about situated (personally familiar) and nonsituated (personally not familiar) conflicts to see whether it makes any difference for student learning. Ebner and Efron (2005) introduced the concept of pseudo-real simulations, which are based on historical and current events from real life that are realistic enough to be familiar to students and yet different enough 
from the actual case so that students can still come up with their own solutions rather than copying what happened in the past. Volkema (2007) introduced real monetary consequences into games, and Honeyman et al. $(2009,2010)$ suggested a number of adventure learning exercises that can take place in real-life settings.

These studies made important contributions to our understanding of how simulations and games can be made more real life relevant. The use of computer-based peace games was rarely explored in this sense as one of the potential teaching methods to overcome some of the criticisms listed above. We know from a study conducted by Wilkenfeld et al. (2005) that there are several benefits of using computerized simulations, such as helping parties to privately organize their information, develop prenegotiation strategies, evaluate and propose mid-negotiation offers, generate prescriptions, and most importantly, aid negotiators in overcoming their cognitive limitations. Thus, a significant advantage of using technology and computer games in simulations could be to increase the real-life complexity in the game as well as to diminish randomness, because this allows decision-making to take place in a more structured and controlled environment. Computer-based peace games can help introduce higher complexity to simulations close to that of a real-life situation. Most of them are based on real historical events (e.g., Israeli-Palestinian conflict) and yet allow enough flexibility to the players to come up with their own actions and solutions so that they do not have to repeat the unfolding history. Computer games can also structure the role-playing of students and, thus, make the learning experience less dependent on student acting skills or avoid cultural stereotyping. Finally, since one of the most important aspects of using simulations is to increase motivation in classroom, computer-based peace games certainly bet higher on that aspect, especially for young generation learners.

In recent years, computer-based peace games have been manufactured to teach students about different skills pertaining to conflicts, especially negotiations. PeaceMaker, a game simulating the Israeli-Palestinian conflict and negotiations, is one such game. It is not only based on a real-life conflict, but also it is one of the most complex simulations of this conflict designed so far for teaching purposes. It is still roleplaying, but students are not isolated from a realistic context, the simulation is more structured, and students are better able to relate to the conflict. The game is inspired by historical real-world events. A player can assume the role of either the Israeli Prime Minister or the Palestinian President and engage in a series of decisions with the aim of satisfying constituents on both sides of the conflict. Impact Games developed this game with the help of advisors in Israel, Palestine, and the United States (Burak, Keylor, \& Sweeney, 2005). The game was also supported by the United States Institute of Peace as an educational tool. Another complex peace game is Global Conflicts, which is the one used in this study and explained in the next section in more detail. Research on the effectiveness of such games is newly emerging.

Few studies have been undertaken in this regard. Most of these are concerned with PeaceMaker. Gonzalez, Saner, and Eisenberg (2013) used PeaceMaker in an experimental study to examine whether it increased the understanding of students about the Israeli-Palestinian negotiations or not. They found that it did contribute to learning about the conflict in a positive manner. Cuhadar and Kampf (2014) conducted another experiment with PeaceMaker in which they assessed the effectiveness of the game in terms of both knowledge acquisition (i.e., learning about the conflict) and attitude change (i.e., attitude toward the conflict and the other side). They also added a cross-cultural assessment to the game by having students from different cultural and political backgrounds (Israeli, Palestinian, American, and Turkish) play it. In this study, they concluded that the game contributed not only to the gaining of knowledge about the narratives of both sides in the conflict, but also to attitude change for those who are not direct parties to the conflict (i.e., Turkish and American students). While the direct parties' attitudes remained the same, Turkish and American students shifted from a more biased toward a more impartial view on the conflict. However, several important questions remain unanswered. Since this study showed that the game had different learning outcomes for different national groups, does being a direct party to a conflict make any difference? How does group identification affect learning and attitude change? Do people learn better if the conflict is one that they closely identify with and are familiar with, or do they learn better if 
they have a blank mind concerning a particular conflict? Does the content and the nature of the conflict matter for learning? Such questions are largely unanswered, and it is these questions we tackle in this study.

Research on attitudes and attitude strength has suggested that people who hold weaker attitudes toward an attitude object more easily change their attitudes, whereas people holding consistent and extreme attitudes are more likely to resist change through social influence (Eagly \& Chaiken, 1998). When attitudes are linked to self-defining values and reference groups, which is often the case in intractable conflicts, they are very much resistant to change. People often reject, reinterpret, or avoid information discrepant with their political identity (Bartels, 2002; Klayman, 1995; Taber \& Lodge, 2006). In this sense, one can expect less change in attitudes for students who belong to groups that are direct parties to the conflict (i.e., Israelis and Palestinians for the Israeli-Palestinian scenario and Guatemalans for the Guatemalan scenario).

On the other hand, more recent research indicates that direct parties to the conflict holding strong attitudes toward the situation change their attitudes if they are presented with information about both sides in the conflict rather than just one side's conflict narrative (Bar-Tal, Halpern, \& Pliskin, in press; Schori-Eyal, Halperin, \& Bar-Tal, 2014). Thus, an Israeli or Palestinian student may change his or her attitudes on the conflict after he or she is exposed to both sides' narrative in the computer game.

In light of this information, all groups, except the Guatemalans, are expected to change their attitudes toward the Guatemalan conflict more easily compared to changing their attitudes toward the IsraeliPalestinian conflict, because recent research also shows that people hold weaker and inconsistent attitudes toward conflicts that are less salient in the global arena, and therefore, they may find it easier to change their attitudes about them (Cohen, 2013).

Druckman and Ebner (2013) argued that they found no significant difference between simulations designed by students in situated (personally relevant and familiar cases) and nonsituated cases (not based on personal experience) in terms of learning effectiveness. However, other scholars argued that there would be a significant difference in learning between scenarios that are personally relevant and not relevant. For instance, Susskind and Corburn (cited in Crampton \& Manwaring, 2008) observed that, while personally relevant simulations may allow students to practice in a realistic context, reality may also create a barrier to behavioral change, because a factually similar context may trigger familiar assumptions and schemas, causing students to fall into existing behavior patterns. In short, there are conflicting opinions within the literature as to how personally relevant situations and conflicts might affect learning as opposed to situations that are not familiar to students.

Following this discussion, we suspect that the content of a simulation is an important factor that should be taken into consideration and may create diverse affects for different groups depending on group identification and how distant or close they physically and emotionally are from that conflict. To better understand the effects of conflict content, we use the Global Conflicts computer game in a systematic experimental assessment with Israeli, Palestinian, Turkish, American, Guatemalan, and Brazilian students.

\section{The Global Conflicts Game}

Global Conflicts is an award-winning educational game developed by Serious Games Interactive in Denmark; it is used for teaching about conflicts, citizenship, geopolitics, and media. The game consists of several different scenarios, each putting the player in a different context, and requires different skills to be employed. The game allows students to explore and learn about different conflicts throughout the world and about the underlying themes of democracy, human rights, globalization, terrorism, climate change and poverty (for more information about the scenarios, see www.globalconflicts.eu). 
Besides the Israeli-Palestinian conflict, which is a high-profile case, the rest of the scenarios in the game are of relatively low profile in the global arena (e.g., Uganda, Rwanda). For this study, we selected the Israeli checkpoint scenario related to the Israeli-Palestinian conflict and the Guatemalan civil war scenario. We selected the former because it is a highly sensitive and very much publicized conflict for Israeli-Jewish and Palestinian students as well as for Turkish and American students, because their countries serve as either third or indirect parties to this conflict. Since this is a salient global conflict, we expect that it would also resonate with Guatemalan and Brazilian students. We selected the Guatemalan scenario because, while this was a low-profile case for Israeli-Jewish, Palestinian, Turkish, and American students, it was a high-profile case for Guatemalan students. The Guatemalan scenario was also expected to be a relatively high-profile case for Brazilian students (definitely compared to Israeli-Jewish, Palestinian, Turkish, and American students), because this case is salient for them in geopolitical and cultural terms, and Brazil tried to mediate between the different groups during the civil war.

The game universe has been designed as a compressed Arabic-Jewish or Guatemalan atmosphere, in $3 \mathrm{D}$, within a contemporary time frame, touching upon the more essential aspects of these situations. In the game, the player is represented by an avatar of a male or female reporter who arrived to the conflict in order to uncover information about the situation through various sources, which collaborate their chosen story. The scenario in the game is based on the real-life accounts reported to human rights organizations and news agencies by victims and witnesses, as well as various other sources.

In the Israeli-Palestinian scenario, the students play the role of a Western reporter whose abilities are being tested during the assignment representing one of the following newspapers: Israeli, Palestinian, or Western. They are expected to produce a news report geared to the audience of one of these newspapers based on the interviews they conduct with various characters at the checkpoint. They are responsible for uncovering information through various sources, which they can quote later on in their news report. At the end of the game, they get to choose some of the quotes they collected throughout the interviews, including them in the final news report on which they are given evaluation. The game score indicates whether the report is placed in the front pages of the newspaper or in the back ones, whether the quotes reflect important pieces of information about the conflict, and whether the quotes well fit the newspaper selected for the assignment.

Those who focus exclusively on pro-Palestinian stories will be able to talk to this side with more ease, while some Israelis might be more apprehensive. They are challenged to keep the work objective while gathering important information to be used in the news report. In the meantime, as the students play the Western reporter in Global Conflicts, they experience the developments in the Israeli-Palestinian conflict and learn about the issues that are important to this conflict. The students have to form an opinion based upon their own actions and after meeting characters that represent different attitudes to the conflict despite the fact that they write for a specific newspaper.

The Guatemalan scenario was concerned with an upcoming election in which one of the political candidates was accused of committing significant human rights violations during the civil war. The Guatemalan Civil War ran from 1960 to 1996. It was mostly fought between the government of Guatemala and various leftist rebel groups supported chiefly by ethnic Mayan indigenous people and Ladino peasants, who together make up the rural poor. The government forces of Guatemala have been accused of committing genocide against the Mayan population of Guatemala during the civil war and were condemned for widespread human rights violations against civilians during this period. Up to 200,000 people died or went missing during the war (Centeno, 2007; Schirmer, 1998).

In the game, there was an attack against the political candidate, which the students were assigned to investigate in the role of a Western journalist. After a lengthy period of gathering information about the background of the civil war in Guatemala, the personal background of the candidate, and the general information about the country, the students engage in an interview with the political candidate. They receive a score at the end that depends on how successfully they use the arguments and information they gathered during their previous research in this interview. 


\section{Research Hypotheses}

The participants were divided into three groups according to the degree to which their national groups relate to each of the two conflicts: direct parties, third parties or indirect parties, and distant parties because recent studies have suggested that these groups differ in their learning outcomes (Cuhadar \& Kampf, 2014; Kampf \& Cuhadar, 2015). Yet, previous research did not compare learning outcomes about different conflicts within each of the three groups as this study does.

Previous studies have suggested that political computer games function as an effective tool for knowledge acquisition for Israeli-Jewish and Palestinian young people, who serve as direct parties to this conflict, and have indicated insignificant differences in learning outcomes between the national groups (Kampf \& Cuhadar, 2015). Therefore, we hypothesize the following:

Hypothesis 1: Participants who are direct parties to the conflict will acquire knowledge about this conflict after playing a game about it.

Recent studies have pointed out that direct parties to the conflict holding strong and consistent attitudes toward the situation may change their attitudes after they are presented with information about the two sides in the conflict rather than just one of them (Bar-Tal et al., in press; Schori-Eyal et al., 2014). The Israeli-Palestinian scenario in the game presents a narrative that represents the hardships of both Israeli soldiers and Palestinian civilians at the checkpoint, whereas the Guatemalan scenario presents a narrative that focuses only on the accusations of the political candidate concerning the human rights violations during the Guatemalan civil war. Thus, we hypothesize the following:

Hypothesis 2: Participants who are direct parties to the Israeli-Palestinian conflict will develop a more impartial attitude about this conflict after playing the game about it, whereas those who are direct parties to the Guatemalan conflict will not change their attitude about this conflict after playing the game about it.

Previous research has suggested that peace games serve as an effective tool for knowledge acquisition for young people who are secondary or third parties to the conflict (Cuhadar \& Kampf, 2014). For example, Cuhadar and Kampf (2014) have shown that, while all parties' (Israeli, Palestinian, Turkish, and American) knowledge about the conflict increased after playing the PeaceMaker game, Turkish and American students' attitudes toward the conflict changed as well and toward a more impartial direction, whereas the Israeli and Palestinian students' attitudes toward the conflict remained the same.

In addition, on the basis of previous research, we expect that the more salient the conflict is in the global arena, the less knowledge will be gained about it from the media, because people start with higher levels of knowledge about salient conflicts and, therefore, have less to gain (i.e., ceiling effect; Cohen, 2013). Given that the Israeli-Palestinian conflict is more salient in the global arena than the Guatemalan conflict, we thus hypothesize the following:

Hypothesis 3: Participants who are from third or secondary parties to the Israeli-Palestinian conflict will acquire less knowledge about this conflict after playing the game about it compared to those belonging to the third or secondary parties to the Guatemalan conflict.

Recent research has shown that third or secondary parties develop a more impartial perspective toward the Israeli-Palestinian conflict after they are presented with a personal and human narrative about the two sides rather than a narrative representing the perspective of just one of the sides (Kampf, 2014). Given that the Israeli-Palestinian scenario in the game introduces a narrative of the daily hardships experienced by both sides in the conflict, while the Guatemalan scenario is a narrative about massive human rights violations toward the Mayan people, we expect to see the following:

Hypothesis 4: Participants who serve as third or secondary parties to the Israeli-Palestinian conflict will develop a more impartial attitude toward the conflict after playing a game about this conflict, whereas participants who 
serve as third or secondary parties to the Guatemalan conflict will not change their attitude about this conflict after playing a game about it.

Studies have indicated that the media are particularly effective in knowledge acquisition for participants who are distant to the conflict and, thus, hold limited knowledge about it (Cohen, 2013). Inconsistent attitudes, in other words attitudes that are not solidified yet, can more easily be changed when confronted with new information (Eagly \& Chaiken, 1998). Yet the less salient the conflict is in the global arena, the more knowledge can be gained about it from the media, because people hold in the beginning scarce knowledge about less salient conflicts and, therefore, have more to gain (Cohen, 2013). Given that the Guatemalan situation is less salient in the global arena than the Israeli-Palestinian conflict, we expect the following:

Hypothesis 5: Participants who are distant to the Guatemalan conflict will acquire more knowledge about this conflict after playing a game about it than those who are distant to the Israeli-Palestinian conflict will acquire about this conflict after playing a game about it.

Following the research on attitude strength, we expect to see that participants are more likely to hold weaker attitudes toward conflicts they feel distant to (geographically and emotionally distant), and therefore, it will be easier for them to take a different perspective with regard to these conflicts after acquiring basic information about them (Eagly \& Chaiken, 1998). People generally hold weaker or inconsistent attitudes toward conflicts, which are less salient in the global arena, and therefore, they may find it easier to change their attitudes about them (Cohen, 2013). Given that the Guatemalan civil war is less salient in the global arena than the Israeli-Palestinian conflict, we expect the following:

Hypothesis 6: Participants who are distant to the Guatemalan conflict (Israeli, Palestinian, Turkish, and American as opposed to Guatemalan and Brazilian) will change their attitude about this conflict after playing a game about it more than those who are distant to the Israeli-Palestinian conflict (i.e., Turkish, American, Guatemalan, and Brazilian) will change their attitude about this conflict after playing a game about it.

\section{Method}

\section{Participants}

A total of 200 undergraduate students, ranging from sophomores to seniors, participated in this study. Forty Israeli-Jewish participants (23 females) were from the Departments of Communication and Political Science at Tel Aviv University, 30 Palestinian students (17 females) were from the Department of Political Science at Al-Quds University, 30 Guatemalan students (15 females) were from the School of Political Science at University of San Carlos of Guatemala, 30 Brazilian students ( 15 females) were from the School of Communication at Sao Paolo University, 40 American students (17 females) were from the Department of Political Science at Wichita State University, and 30 Turkish students (12 females) were from the Department of Political Science at Bilkent University.

A chi-square test of gender and nationality showed insignificant results $\left(\chi^{2}=6.45, p=n s\right)$, indicating that the six groups were equally divided by gender. A one-way ANOVA of nationality as a between-subjects factor and age as a within-subjects factor showed that Israeli-Jewish participants were significantly older $(M=25.09, S D=2.08)$ than Palestinian participants $(M=21.07, S D=1.59)$, Guatemalan participants $(M=21.08 S D=1.45)$, American participants $(M=22.04, S D=4.45)$, Brazilian participants $(M=20.06, S D=1.14)$, and Turkish participants $(M=22.02, S D=1.94), F(5,194)=14.18, p<.001$. This difference is due to the fact that Israelis serve a period of 3-4 years in the army before studying at university. 


\section{Design and Procedure}

The study was conducted as part of classes dealing with various aspects of political science and conflict resolution where students received credit for their participation. The data on students from University of San Carlos, Wichita State University, Sao Paolo University, and Bilkent University were collected in March 2013, the data on students from Tel Aviv University were collected in April 2013, and the data on students from Al-Quds University were collected in June 2013. Data collection in Guatemala, Turkey, Brazil, and the United States was completed before the trial of Rios Montt, the President of Guatemala during the civil war, was widely publicized and completed. Data collection in Israel and Palestine was conducted after this trial was completed, but this trial received minor coverage in the news media mainly in the section of international news, which receives less attention by young people (Cohen, 2013), so it was unlikely to bias the data collection.

The study took up to 3 hours and included four parts. First, participants were introduced to the Global Conflicts game and played a short demo. Second, they filled in a short questionnaire. Third, participants played the two scenarios in the game in random order. Finally, after playing the two scenarios the participants again filled in a short questionnaire. The questionnaires used before and after the game were almost identical in content with the exception of a few additional questions in the postgame questionnaire deliberating participants' experience with the game.

\section{Measures}

As our measure of knowledge about the Israeli-Palestinian conflict, students were asked a battery of 21 open-ended and close-ended knowledge questions on various political and historical aspects of the Israeli-Palestinian conflict, varying in degrees of difficulty, such as "Name the parties to the 1993 Oslo agreement," "Who is covered in the Right of Return," and "What is the meaning of the Nakba Day." This measure has already been used in previous studies, which examined PeaceMaker's effectiveness regarding knowledge acquisition among participants who are direct parties to the conflict (i.e., Israeli-Jews and Palestinians) and those who are third or secondary parties (i.e., Turks and Americans; Cuhadar \& Kampf, 2014). The coding differentiated between correct answers, don't know answers, and incorrect answers. To measure knowledge acquisition, we focused on the number of correct answers in the two questionnaires.

As our measure of background knowledge about the Guatemalan civil war, students were asked a battery of 19 open-ended and close-ended knowledge questions on various political and historical aspects of the civil war in Guatemala, varying in degrees of difficulty, such as "What is impunity," "Who is URNG," and "When did the civil war run in Guatemala." These questions were taken from historical and political publications that examined the civil war in Guatemala (Centeno, 2007; Schirmer, 1998). The coding differentiated between correct answers, don't know answers, and incorrect answers. To measure knowledge acquisition, we focused on the number of correct answers in the two questionnaires.

To assess attitudes in the Israeli-Palestinian conflict, we examined what participants thought about "how right each side is" on key issues in the conflict. The issues included water, refugees, borders, settlements, Jerusalem, and security using the following scale: (a) Palestinians are absolutely right; (b) Palestinians are somewhat right; (c) Both sides are equally right; (d) Israelis are somewhat right; and (e) Israelis are absolutely right. After conducting a factor analysis, the average of answers given on the six key issues was used as a measure of attitude change about the conflict before and after playing the game. This measure has already been used in previous studies conducted with PeaceMaker examining attitude change and perspective taking of participants who are direct parties to the Israeli-Palestinian conflict and those who are third or secondary parties in the conflict (Cuhadar \& Kampf, 2014).

We assessed attitudes about the Guatemalan civil war by a series of six statements from the game advocating various angles on the situation. We selected statements that indicated key points in the civil war 
based on historical and political studies about the situation (Centeno, 2007; Schirmer, 1998). Participants were required to indicate how much they agree with each statement on a 5-point scale in which 1 and 2 indicated agreement with the various leftist rebel groups supported chiefly by ethnic Mayan indigenous people and Ladino peasants, who together make up the rural poor in the civil war, and 4 and 5 indicated support for the government forces in this war. The third category indicated no idea, and we included this category because the Guatemalan scenario is a low-profile case for Israeli-Jewish, Turkish, American, and Palestinian participants, and they may not have any solid attitude about it before playing the game. After conducting a factor analysis, the average of answers given on the six statements was used as a measure of attitude change in the conflict before and after playing the game.

We measured the relevance (the extent of familiarity and attachment) of the Guatemalan and the Israeli-Palestinian conflicts to the participant, because as discussed in the discussion on hypotheses, it indicates attitude strength, which is closely related to taking a different perspective in the conflict (Eagly \& Chaiken, 1998). It was measured by two questions. The first question examined how much the participant cares about each of the two conflicts. A 4-point scale was used in this question, where 1 represented uninterested at all and 4 represented very much interested. The second question examined how important each of the two conflicts to the participant's country. A 5-point scale was used in this question, where 1 represented not important at all and 5 represented extremely important.

\section{Procedures}

We conducted a repeated-measures ANOVA to test our research hypotheses. We investigated the effect of playing the game on knowledge acquisition and attitude change at two separate time points: pre- and postgame intervention.

\section{Results}

\section{Relevance: Interest and Importance}

We conducted a repeated-measures ANOVA with interest in the Israeli-Palestinian conflict and interest in the Guatemalan civil war as within subjects factor and nationality as a between-subjects factor. The interaction between these factors was significant, $F(6,194)=2.23, p<.0001, \eta^{2}=.74$, (simple effects: Americans $F[1,194]=11.74, p<.0001$; Turks $F[1,194]=55.17, p<.0001$; Israelis $F[1,194]=246.65$, $p<.001$; Brazilians $F[1,194]=116.42, p<.001$; Guatemalans $F[1,194]=255.22, p<.001$; Palestinians $F[1,194]=232.88, p<.001)$. Israeli-Jews, Palestinians, Turks, and Americans $(M=3.39$, $S D=0.49 ; M=3.3, S D=0.48 ; M=2.25, S D=0.59 ; M=2.28, S D=0.78$, respectively) were more interested in the Israeli-Palestinian conflict than in the Guatemalan civil war $(M=1.51, S D=0.68$; $M=1.2, S D=0.41 ; M=1.22, S D=0.46 ; M=1.12, S D=.38$, respectively). In contrast, Guatemalans and Brazilians were more interested in the Guatemalan civil war $(M=3.8, S D=0.41 ; M=2.78$, $S D=0.78$, respectively) than in the Israeli-Palestinian conflict $(M=1.57, S D=0.51 ; M=1.78$, $S D=0.65$, respectively) (Table 1 ). In both scenarios, participants who are direct parties to the conflict were more interested in that particular conflict than those who are third or secondary parties.

Similarly, we conducted a repeated-measures ANOVA with the importance of the Israeli-Palestinian conflict and the importance of the Guatemalan civil war as within-subjects factors and nationality as a between-subjects factor. The interaction between these factors was significant as well, $F(6,194)=5.32$, $p<.013, \eta^{2}=.44$, (simple effects: Americans $F[1,194]=65.32, p<.0001$; Turks $F[1,194]=64.83$, $p<.0001$; Israelis $F[1,194]=534.09, p<.001$; Brazilians $F[1,194]=211.49, p<.001$; Guatemalans $F[1,194]=351.15, p<.001$; Palestinians $F[1,194]=505.66, p<.001)$. Israeli-Jewish, Palestinian, Americans, and Turks perceived the Israeli-Palestinian conflict $(M=4.99, S D=0.12 ; M=4.95$, $S D=0.12 ; M=4.85, S D=0.15 ; M=4.89, S D=0.18$, respectively) as more important to their country 
Table 1

Interest: Israeli-Palestinian Conflict Versus Guatemalan Civil War

\begin{tabular}{lcr}
\hline & \multicolumn{1}{l}{$\begin{array}{l}\text { Israeli-Palestinian Conflict } \\
M(S D)\end{array}$} & $\begin{array}{l}\text { Guatemalan Civil War } \\
M(S D)\end{array}$ \\
\hline Israeli-Jews & $3.39(0.49)$ & $1.51(0.68)$ \\
Palestinians & $3.3(0.48)$ & $1.2(0.41)$ \\
Turks & $2.25(0.59)$ & $1.22(0.46)$ \\
Americans & $2.28(0.78)$ & $1.12(0.38)$ \\
Guatemalans & $1.57(0.51)$ & $3.8(0.41)$ \\
Brazilians & $1.78(0.65)$ & $2.78(0.78)$ \\
\hline
\end{tabular}

than the Guatemalan civil war $(M=1.83, S D=0.92 ; M=1.4, S D=0.62 ; M=1.85, S D=0.78$; $M=1.23, S D=0.52$, respectively). In contrast, Guatemalans and Brazilians perceived the Guatemalan civil war as more important to their country $(M=4.95, S D=0.78 ; M=3.84, S D=0.69$, respectively) than the Israeli-Palestinian conflict $(M=2.7, S D=0.79 ; M=2.55, S D=0.62$, respectively). Yet, Guatemalan and Brazilian participants perceived the Israeli-Palestinian conflict as more important to their country than Israeli-Jewish, Palestinian, Turkish, and American participants perceived the Guatemalan civil war to their country (Table 2).

\section{Direct Parties to the Conflict: Knowledge Acquisition}

To investigate the game effects on knowledge acquisition for direct parties, we used our measure of knowledge acquisition before playing the game, in which we assessed the total number of correct answers before playing the game for the Israeli-Palestinian conflict, for Israeli-Jewish and Palestinian participants, and the total number of correct answers before playing the game for the Guatemalan conflict for Guatemalan participants. A similar measure was used for knowledge acquisition for direct parties after playing the game.

A repeated-measures ANOVA was conducted, with knowledge acquisition for direct parties (i.e., before and after playing the game) as a within-subjects factor and nationality (Israeli, Guatemalan, or Palestinian) as a between-subjects factor. The interaction between the two measures was insignificant, $F$ $(2,98)=.592, n s, \eta^{2}=.012$. To put it differently, although all direct parties acquired knowledge from the game, $F(1,99)=196.37, p<.0001, \eta^{2}=.67$, there were insignificant differences between the three national groups in this respect (Table 3). Israeli-Jews acquired more knowledge after playing the Israeli-Palestinian game than before playing it (before: $M=16.1, S D=2.04$; after: $M=18.3$, $S D=1.67)$. Similarly, Palestinians acquired more knowledge after playing the Israeli-Palestinian game than before playing it (before: $M=15.1, S D=2.14$; after: $M=17.13, S D=1.63$ ). Finally, Guatemalans

Table 2

Importance: Israeli-Palestinian Conflict Versus Guatemalan Civil War

\begin{tabular}{lcr}
\hline & \multicolumn{1}{l}{ Israeli-Palestinian Conflict } & $\begin{array}{l}\text { Guatemalan Civil War } \\
M(S D)\end{array}$ \\
\hline Israeli-Jews & $M(S D)$ \\
Palestinians & $4.99(0.12)$ & $1.83(0.92)$ \\
Turks & $4.95(0.12)$ & $1.4(0.62)$ \\
Americans & $4.85(0.15)$ & $1.23(0.52)$ \\
Guatemalans & $4.89(0.18)$ & $1.85(0.78)$ \\
Brazilians & $2.7(0.79)$ & $4.95(0.25)$ \\
\hline
\end{tabular}


Table 3

Knowledge Acquisition for Direct Parties

\begin{tabular}{lcc}
\hline & \multicolumn{1}{l}{ Before playing the game } \\
$M(S D)$ & $\begin{array}{l}\text { After playing the game } \\
M(S D)\end{array}$ \\
\hline Israeli-Jews & $16.1(2.04)$ & $18.3(1.67)$ \\
Palestinians & $15.1(2.14)$ & $17.13(1.63)$ \\
Guatemalans & $15.73(1.04)$ & $17.53(0.63)$ \\
\hline
\end{tabular}

acquired more knowledge after playing the Guatemalan game than before playing it (before: $M=15.73$, $S D=1.04$; after: $M=17.53, S D=0.63)$.

\section{Direct Parties: Attitude Change}

To investigate the game effects on attitude change for direct parties, we used our measure of attitudes for direct parties before playing the game, which evaluated the average of answers given on the six key issues concerning the Israeli-Palestinian conflict before playing the game, for Israeli-Jewish and Palestinian participants, and the average of answers given on the six statements concerning the Guatemalan conflict before playing the game in for Guatemalan participants. A similar measure was used for attitudes for direct parties after playing the game.

A repeated-measures ANOVA was conducted, with attitudes for direct parties (i.e., before and after playing the game) as a within-subjects factor, nationality (Israeli, Guatemalan, or Palestinian) as a between-subjects factor, and political attitudes as covariate. The interaction between attitudes for direct parties and political ideology was insignificant. The interaction between attitudes for direct parties and nationality was significant, $F(2,98)=3.88, p<.05, \eta^{2}=.073$ (simple effects: Israelis $F[1,98]=48.29$, $p<.0001$; Palestinians $F[1,98]=31.00, p<.0001$; Guatemalans $F[1,98]=0.69, n s)$. This result means that Israeli-Jews held a more pro-Israeli view before playing the Israeli-Palestinian game $(M=3.88$, $S D=0.59)$ and were closer to thinking that both Israeli and Palestinian sides were equally right regarding key issues in the conflict after playing it $(M=3.35, S D=0.66)$. Palestinians held a very pro-Palestinian view before playing the Israeli-Palestinian game $(M=1.07, S D=0.09)$ and were closer to thinking that both sides were equally right after playing it $(M=2.03, S D=0.11)$. Guatemalans held a very pro-Mayan view before playing the Guatemalan game $(M=1.41, S D=0.226)$, and they did not change their attitude after playing it $(M=1.51, S D=0.23$; Table 4$)$.

\section{Third and Secondary Parties: Knowledge Acquisition}

To investigate the game effects on knowledge acquisition for third or secondary parties, we used our measure of knowledge acquisition before playing the game, which evaluated the total number of correct answers before playing the game for the Israeli-Palestinian conflict, in the case of Turkish and American

Table 4

Attitude Change for Direct Parties

\begin{tabular}{lll}
\hline & $\begin{array}{l}\text { Before playing the game } \\
M(S D)\end{array}$ & $\begin{array}{l}\text { After playing the game } \\
M(S D)\end{array}$ \\
\hline Israeli-Jews & $3.88(0.59)$ & $3.35(0.66)$ \\
Palestinians & $1.07(0.09)$ & $2.03(0.11)$ \\
Guatemalans & $1.41(0.26)$ & $1.51(0.23)$ \\
\hline
\end{tabular}


participants, and the total number of correct answers before playing the game for the Guatemalan conflict in the case of Brazilian participants. A similar measure was used for knowledge acquisition for third parties after playing the game.

A repeated-measures ANOVA was conducted, with knowledge acquisition for third parties (i.e., before and after playing the game) as a within-subjects factor and nationality (Turkish, American, and Brazilian) as a between-subjects factor. The interaction between the two measures was significant, $F(2,98)=2.88, p<.01, \eta^{2}=.063$ (simple effects: Brazilians $F[1,98]=57.94, p<.0001$; Americans $F[1,98]=47.15, p<.001$; Turks $F[1,98]=30.15, p<.0001)$. Brazilians acquired more knowledge after playing the Guatemalan game (before: $M=7.99, S D=1.98$; after: $M=13.32, S D=1.97$ ) than Americans (before: $M=4.36, S D=1.04$; after: $M=8.69, S D=1.56$ ) and Turks (before: $M=6.58, S D=1.12$; after: $M=8.73, S D=1.37$ ) acquired after playing the Israeli-Palestinian game (Table 5).

\section{Third and Secondary Parties: Attitude Change}

To investigate the game effects on attitude change for third parties, we used our measure of attitudes before playing the game, which assessed the average of answers given on the six key issues concerning the Israeli-Palestinian conflict, for American and Turkish participants, and the average of answers given on the six statements concerning the Guatemalan conflict for Brazilian participants. A similar measure was used for attitudes for third parties after playing the game as well.

A repeated-measures ANOVA was conducted, with attitudes of third parties (i.e., before and after playing the game) as a within-subjects factor, nationality (Brazilian, Turkish, and American) as a between-subjects factor, and political attitudes as covariate. The interaction between attitudes of third parties and political ideology was insignificant. The interaction between attitudes of third parties and nationality was significant, $F(2,98)=4.58, p<.01, \eta^{2}=.103$ (simple effects: Brazilians $F[1,98]=0.58$, $n s$; Americans $F[1,98]=106.64, p<.001$; Turks $F[1,98]=21.84, p<.0001)$. That is, Brazilians held a pro-Mayan view before playing the Guatemalan game $(M=1.93, S D=0.46)$ and did not change their attitude after playing it $(M=1.39, S D=0.34)$. Americans held a pro-Israeli view before playing the Israeli-Palestinian game $(M=3.7, S D=0.65)$ and were closer to thinking that both Israeli and Palestinian sides were equally right regarding key issues in the conflict after playing it $(M=2.92, S D=0.66)$. Turks held a pro-Palestinian view before playing the Israeli-Palestinian game $(M=1.86, S D=0.12)$ and were closer to thinking that both sides are equally right after playing it $(M=2.33, S D=0.13$; Table 6$)$.

Table 5

Knowledge Acquisition for Third Parties

\begin{tabular}{llc}
\hline & $\begin{array}{l}\text { Before playing the game } \\
M(S D)\end{array}$ & $\begin{array}{l}\text { After playing the game } \\
M(S D)\end{array}$ \\
\hline Brazilians & $7.99(1.98)$ & $13.32(1.97)$ \\
Turks & $6.58(1.12)$ & $8.73(1.37)$ \\
Americans & $4.36(1.04)$ & $8.69(1.56)$ \\
\hline
\end{tabular}

Table 6

Attitude Change for Third Parties

\begin{tabular}{lll}
\hline & Before playing the game & After playing the game \\
& $M(S D)$ & $M(S D)$ \\
\hline Brazilians & $1.93(0.46)$ & $1.39(0.34)$ \\
Turks & $1.86(0.12)$ & $2.33(0.13)$ \\
Americans & $3.7(0.65)$ & $2.92(0.66)$ \\
\hline
\end{tabular}




\section{Distant Parties: Knowledge Acquisition}

To investigate the game effects on knowledge acquisition for distant parties (i.e., parties who are geographically and emotionally distanced from the conflict), we used our measure of knowledge acquisition before playing the game, which assessed the total number of correct answers for the Israeli-Palestinian conflict, in the case of Brazilian and Guatemalan participants, and the total number of correct answers for the Guatemalan conflict in the case of Israeli, Palestinian, Turkish, and American participants. A similar measure was used for knowledge acquisition for distant parties after playing the game.

A repeated-measures ANOVA was conducted, with knowledge acquisition for distant parties (i.e., before and after playing the game) as a within-subjects factor and nationality (Israeli, Palestinian, Guatemalan, Turkish, American, and Brazilian) as a between-subjects factor. The interaction between the two measures was significant, $F(6,194)=2.95, p<.001, \eta^{2}=.143$ (simple effects: Americans $F[1$, $194]=327.56, p<.001$; Turks $F[1,194]=104.18, p<.001$; Israelis $F[1,194]=538.57, p<.001$; Palestinians $F[1,194]=565.65, p<.001$; Brazilians $F[1,194]=83.89, p<.0001$; Guatemalans $F[1$, $194]=110.20, p<.001$ ). American (before: $M=4.07, S D=0.98$; after: $M=14.31, S D=1.77$ ), Turkish (before: $M=1.27, S D=0.18$; after: $M=7.69, S D=1.58$ ), Israeli (before: $M=1.46, S D=0.28$; after: $M=13.10, S D=1.79$ ), and Palestinian (before: $M=0.53, S D=0.18$; after: $M=14.47$, $S D=2.56$ ) participants acquired more knowledge about the Guatemalan conflict than Brazilian (before: $M=8.19, S D=1.67$; after: $M=11.43, S D=1.43$ ) and Guatemalan (before: $M=9.38, S D=2.15$; after: $M=13.57, S D=2.17$ ) participants acquired from the Israeli-Palestinian conflict (Table 7).

\section{Distant Parties: Attitude Change}

To investigate the game effects on attitude change for distant parties, we used our measure of attitudes before playing the game, which evaluated the average of answers given on the six key issues concerning the Israeli-Palestinian conflict before playing the game, for Guatemalan and Brazilian participants, and the average of answers given on the six statements concerning the Guatemalan conflict before playing the game for Israeli, Palestinian, Turkish, and American participants. A similar measure was used for attitudes for distant parties after playing the game.

A repeated-measures ANOVA was conducted, with attitudes for distant parties (i.e., before and after playing the game) as a within-subjects factor, nationality (Israeli, Palestinian, Guatemalan, Brazilian, Turkish, and American) as a between-subjects factor, and political attitudes as covariate. The interaction between attitudes of distant parties and political ideology was insignificant. The interaction between attitudes of distant parties and nationality was significant, $F(6,194)=5.65, p<.001, \eta^{2}=.21$ (simple effects: Americans $F[1,194]=286.77, p<.001$; Turks $F[1,194]=45.49, p<.0001$; Israelis $F[1$, $194]=251.34, p<.001 ;$ Palestinians $F[1,194]=487.21, p<.001$; Brazilians $F[1,194]=89.69$, $p<.001$; Guatemalans $F[1,194]=64.17, p<.0001)$. Brazilians $(M=2.04, S D=0.86)$ and Guatemalans

Table 7

Knowledge Acquisition for Distant Parties

\begin{tabular}{llc}
\hline & $\begin{array}{l}\text { Before playing the game } \\
M(S D)\end{array}$ & $\begin{array}{l}\text { After playing the game } \\
M(S D)\end{array}$ \\
\hline Israeli-Jews & $1.46(0.28)$ & $13.10(1.79)$ \\
Palestinians & $0.53(0.18)$ & $14.47(2.56)$ \\
Turks & $1.27(0.18)$ & $7.69(1.58)$ \\
Americans & $4.07(0.98)$ & $14.31(1.77)$ \\
Guatemalans & $9.38(2.15)$ & $13.57(2.17)$ \\
Brazilians & $8.19(1.67)$ & $11.43(1.43)$ \\
\hline
\end{tabular}


Table 8

Attitude Change for Distant Parties

\begin{tabular}{lll}
\hline & $\begin{array}{l}\text { Before playing the game } \\
M(S D)\end{array}$ & $\begin{array}{l}\text { After playing the game } \\
M(S D)\end{array}$ \\
\hline Israeli-Jews & $2.98(0.12)$ & $1.93(0.49)$ \\
Palestinians & $3.04(0.54)$ & $1.26(0.13)$ \\
Turks & $2.92(0.52)$ & $2.03(1.01)$ \\
Americans & $2.88(0.45)$ & $1.75(0.12)$ \\
Guatemalans & $2.06(0.69)$ & $2.82(1.13)$ \\
Brazilians & $2.04(0.86)$ & $2.93(1.02)$ \\
\hline
\end{tabular}

$(M=2.06, S D=0.69)$ held a pro-Palestinian view before playing the Israeli-Palestinian game and were closer to thinking that both Israeli and Palestinian sides were equally right regarding key issues in the conflict after playing it $(M=2.93, S D=1.02 ; M=2.82, S D=1.13$, respectively). Israeli-Jews, Palestinians, Turks, and Americans did not have any solid view about the Guatemalan civil war before playing the game $(M=2.98, S D=0.12 ; M=3.04, S D=0.54 ; M=2.92, S D=0.52$; and $M=2.88, S D=0.45$, respectively), and after playing it they got closer to hold a pro-Mayan view $(M=1.93, S D=0.49$; $M=1.26, S D=0.13 ; M=2.03, S D=1.01 ;$ and $M=1.75, S D=0.12$, respectively; Table 8 ).

\section{Discussion}

As far as our hypotheses are concerned, we found support for Hypothesis 1 . All parties to the conflict acquired more knowledge about the particular conflict regardless of the type and content of the conflict. Israeli-Jews and Palestinians acquired more knowledge about the Israeli-Palestinian conflict after playing the game; likewise, Guatemalan participants acquired higher level of knowledge about the Guatemalan civil war after playing the game. Furthermore, all groups' knowledge levels increased concerning whichever game they played.

When direct parties' attitudes toward the conflict are concerned, we also found support for our second hypothesis. In line with our expectations, while the Israeli-Jewish and Palestinian attitudes moved from an ethnocentric position toward a more impartial one, the attitudes of the Guatemalan participants toward the conflict have not changed and remained pro-Mayan. This is consistent with our expectation about the different nature of these two conflicts, the former between two conflicting sides with two competing narratives while the latter one represented a one-sided conflict narrative in the game centered on massive human rights violations against the Mayan people.

As far as third and secondary parties to the conflict are concerned, we found support for both the third and fourth hypotheses. Brazilian participants acquired more knowledge of the Guatemalan conflict than the knowledge Turkish and American students acquired about the Israeli-Palestinian conflict. This is due to the ceiling effect we discussed earlier and because the Israeli-Palestinian conflict is a high-profile case at the global level. However, even though it is more high profile than the Guatemalan conflict at the global level, Brazilian students still indicated that Guatemalan conflict is more relevant to them and to their country due to its geographic and perhaps cultural closeness. As far as attitudes of third parties are concerned, our hypothesis was again supported. While Brazilian students did not change their pro-Mayan attitude after playing the game, American and Turkish students changed their attitude toward a more impartial one. American students moved from a pro-Israeli attitude toward an impartial one (i.e., both sides are right), while a similar shift happened for Turkish students from a pro-Palestinian position toward an impartial position.

Finally, when distant parties were concerned, we found support for Hypothesis 5. Our expectations hold out in this case because Israeli-Jewish, Palestinian, Turkish, and American participants acquired 
more knowledge about the Guatemalan conflict than the Brazilian and Guatemalan participants acquired about the Israeli-Palestinian conflict. This is due to the more global nature of the Israeli-Palestinian conflict. When Hypothesis 6 is concerned, our expectation was partially supported though. All groups changed their initial attitudes toward both conflicts. As we expected, Israeli-Jewish, Palestinian, Turkish, and American participants' attitudes changed and became more pro-Mayan. However, the pro-Palestinian attitudes of Brazilian and Guatemalan participants also changed (similar to those of third or secondary parties) toward a more balanced attitude (i.e., both sides are right), which was contrary to our expectation.

\section{Conclusion}

This study shows that the content and the type of conflict used in a conflict simulation make a difference on the learning outcomes. Two things matter in this sense: the nature of the conflict (Israeli-Palestinian vs. Guatemalan in this case) and who is at the receiver end (direct parties, third parties, distant parties). It is not only the global salience of a conflict but also the degree of acquaintance and attachment to the conflict that matters in terms of learning outcomes.

While the simulations increased the level of knowledge about that particular conflict in all groups, regardless of the content and type of the conflict, which is in line with the findings of Cuhadar and Kampf (2014) concerning the PeaceMaker game, when attitude change is concerned the effects diversify more from one group to the other. This result seems to be in line with Druckman and Ebner's (2013) finding that, when enhancing knowledge is the goal of the simulation (mentioned as concept learning in their article), using situated (personally relevant) versus nonsituated (personally distant) simulations does not matter. Any type of content, relevant or not, results in increasing knowledge.

However, when perspective taking is concerned, the content of the simulation matters. Therefore, if the goal of the simulation exercise is to pave the way to conflict resolution by enhancing perspective taking, empathy between the two sides and the like, the content of the conflict used in the simulation and game may be more important. Thus, we suggest that, when instructors select simulations for teaching conflict and negotiation skills, they should pay close attention to the following: the goals of the exercise, the salience of that conflict for students, and students' group identification within the group receiving the instruction, as different parties will get different learning outcomes from the same conflict as well as from different types of conflict. Lastly, learning differs according to the conflict narrative, whether it presents the story from both sides' perspectives and is a globally salient one, or whether it presents a story in which there is a clear victim and is less salient globally.

In sum, there are variations between the two scenarios, especially due to the different nature of the conflicts, but it is promising to see that the game was effective in generating perspective taking for Israeli-Jewish and Palestinian students with regard to their own conflict, especially since they hold strong attitudes on the issues. This is incongruous with the findings from Cuhadar and Kampf's (2014) study on PeaceMaker, where attitude change and perspective taking was identified only for those who were not direct parties to the conflict (i.e., Turks and Americans). Two possible explanations can be suggested to the different learning outcomes of the two games, which require further studies in the future. First, PeaceMaker focuses on the perspective of the Israeli Prime Minister and the Palestinian President to the Middle Eastern situation, while Global Conflicts focuses on the perspective of Israeli soldiers and Palestinian people in the checkpoint. The latter is a more personal and human perspective on the situation than the former, and therefore, young Israeli and Palestinian participants may find it easier to identify and empathize with the different perspectives. In addition, Global Conflicts may be a more immersive game environment than PeaceMaker. The immersion effect creates an environment in which the players submerge themselves and progressively increase their attention and concentration in this environment, resulting in more positive effects on memory retention, attitude change, and knowledge acquisition (Raphael, Bachen, \& Hernández-Ramos, 2012; Yan \& Cordry, 2011). 
On the basis of our findings, we can say that computer games such as Global Conflicts can serve as an effective tool for peace education for two key considerations, which require another study in the future. First, peace games are uniquely suited to illustrate complex issues, such as the Israeli-Palestinian conflict or the Guatemalan civil war, in a very engaging and interactive way compared to other more passive and linear media (Gee, 2008). In this sense, they facilitate the participants' gaining of a conceptually complex view of the conflict as opposed to the simplistic and polarized view of the conflict often presented in collective narratives and mainstream socialization agents in a conflict environment. Achieving this, computer games can thus be a tool for legitimating the other's narrative in a way that events are seen from both perspectives. This is an important step toward increasing learning about the outgroup and the conflict dynamics, as indicated by social and political psychologists working on intergroup conflict, which is a necessary step toward attitude change and reducing intergroup tensions.

Second, by facilitating role-taking from both sides, Global Conflicts intends to provide a unique opportunity to inform people of the issues in the conflict and influence their attitudes toward the other side. In games such as Global Conflicts, we can differentiate between basic learning in the game, aiming at acquiring knowledge and collecting data, and deeper learning beyond the game aiming at changing the players' perspectives regarding the situation (Mitgutsch, 2011). In fact, previous studies have indicated that playing a game that elicits role-taking resulted in greater knowledge acquisition and greater attitude change than reading a text conveying the same information (Bogost, 2007; Peng, Lee, \& Heeter, 2010).

The results comparing the effectiveness of the two scenarios in the Global Conflicts game are promising in terms of showing that computer-based peace games can be used not only for teaching purposes in courses related to conflict and peace studies but also as part of peace building trainings. Our results indicate that they are useful not only in teaching a more complex view of the conflict to the parties, particularly to those who are direct parties to the conflict with strong attitudes on the issues, but also in engendering attitude change especially in the form of taking a more balanced perspective and being able to look at the conflict from both lenses. However, it is also important to note the different results obtained from the Israeli-Palestinian versus the Guatemalan scenarios. The framing of the story may be crucial (i.e., a troubled checkpoint where the Israeli soldiers and Palestinian civilians are both stressed about their security as opposed to a political candidate who is clearly an oppressor who conducted massive human rights abuses toward the poor and weak people) in determining whether the players will gain the perspective of both sides or not.

\section{References}

Alexander, N., \& LeBaron, M. (2009). Death of the role play. In C. Honeyman, J. Coben, \& G. DePalo (Eds.), Second generation negotiation teaching (Vol. 1, pp. 179-197). St. Paul, MN: DRI Press.

Bar-Tal, D., Halpern, E., \& Pliskin, R. (in press). Why is it so difficult to resolve intractable conflicts peacefully? A socio-psychological explanation. In M. Galluccio (Ed.), Handbook of international negotiation: Interpersonal, intercultural, and diplomatic perspective (pp. 73-92). New York, NY: Springer.

Bartels, L. (2002). Beyond the running tally: Partisan bias in political perceptions. Political Behavior, 24, 117-150. doi:10.1023/A:1021226224601

Bogost, I. (2007). Persuasive games. Cambridge, UK: MIT Press.

Brown, S., Boyer, M., Mayall, H., Johnson, P., Meng, L., Butler, M., et al. (2003). The GlobalEd Project: Gender differences in a problem-based learning environment of international negotiations. Instructional Science, 31, 255-276. doi:10.1023/A:1024677708501

Burak, A., Keylor, E., \& Sweeney, T. (2005). PeaceMaker: A video game to teach peace. In M. Maybury, O. Stock, \& W. Wahlster (Eds.), Intelligent technologies for interactive entertainment (Vol. 3814, pp. 307-310). Berlin and Heidelberg, Germany: Springer.

Centeno, M. (2007). Warfare in Latin America. Hampshire, UK: Ashgate.

Cohen, A. A. (2013). Foreign news on television: Where in the world is the global village? New York, NY: Peter Lang. 
Crampton, A., \& Manwaring, M. (2008). Reality and artifice in teaching negotiation: The variable benefits of 'keeping it real' in simulations. Teaching Negotiation, 2(1). Retrieved from http://archive.constantcontact.com/ fs079/1101638633053/archive/1102208945307.html\#LETTER.BLOCK8.

Cuhadar, E., \& Kampf, R. (2014). Learning about conflict and negotiations through computer simulations: The case of PeaceMaker. International Studies Perspectives, 15, 509-524. doi:10.1111/insp.12076

Druckman, D. (2011). Negotiation and mediation. In J. N. Druckman, D. P. Green, J. H. Kuklinski, \& A. Lupia (Eds.), Cambridge handbook of experimental political science (pp. 413-429). New York, NY: Cambridge University Press.

Druckman, D., \& Ebner, N. (2008). Onstage or behind the scenes? Relative learning benefits of simulation roleplay and design. Simulation \& Gaming, 39, 465-497. doi:10.1177/1046878107311377

Druckman, D., \& Ebner, N. (2013). Games, claims, and new frames: Rethinking the use of simulation in negotiation education. Negotiation Journal, 29, 61-93. doi:10.1111/nejo.12005

Eagly, A., \& Chaiken, S. (1998). Attitude structure and function. In T. D. Gilbert, S. T. Fiske, \& G. Lindzey (Eds.), The handbook of social psychology (pp. 269-322). New York, NY: McGraw-Hill.

Ebner, N., \& Efron, Y. (2005). Using tomorrow's headlines for today's training: Creating pseudo-reality in conflict resolution simulation games. Negotiation Journal, 21, 377-394. doi:10.1111/j.1571-9979.2005.00070.x

Gee, J. P. (2008). Learning and games. In K. Salen (Ed.), The ecology of games: Connecting youth, games, and learning (pp. 21-40). Cambridge, MA: MIT Press.

Gehlbach, H., Brown, S. W., Ioannou, A., Boyer, M. A., Hudson, N., Niv-Solomon, A., et al. (2008). Increasing interest in social studies: Social perspective taking and self-efficacy in stimulating simulations. Contemporary Educational Psychology, 33, 894-914. doi:10.1016/j.cedpsych.2007.11.002

Gonzalez, C., Saner, L. D., \& Eisenberg, L. Z. (2013). Learning to stand in the other's shoes: A computer video game experience of the Israeli-Palestinian conflict. Social Science Computer Review, 31, 236-243. doi:10.1177/ 0894439312453979

Honeyman, C., Coben, J., \& De Palo, G. (2009). Introduction: Negotiation teaching 2.0. Negotiation Journal, 25, 141-146. doi:10.1111/j.1571-9979.2009.00215.x

Honeyman, C., Coben, J., \& De Palo, G. (2010). Venturing beyond the classroom. Vol. 2. St. Paul, MN: DRI Press.

Kampf, R. (2014). Playing Singly, Playing in Dyads in a computerized simulation of the Israeli-Palestinian Conflict. Computers in Human Behavior, 32, 9-14.

Kampf, R., \& Cuhadar, E. (2015). Do computer games enhance learning about conflicts? A cross-national inquiry into proximate and distant scenarios in Global Conflicts. Computers in Human Behavior, 52, 541-549.

Kersten, G. E., Koszegi, S., \& Vetschera, R. (2003). The effects of culture in computer mediated negotiations: Experiments in 10 countries. Journal of Information Technology Theory Applied, 5(21), 1-28.

Klayman, J. (1995). Varieties of confirmation bias. Psychology of Learning and Motivation, 32, 385-418. doi:10.1016/S0079-7421(08)60315-1

Lewicki, R. J. (2000). Teaching negotiation and dispute resolution in colleges of business: The state of the practice. In M. Wheeler (Ed.), Teaching negotiation: Ideas and innovations (pp. 169-185). Cambridge, MA: PON Books.

Loewenstein, J., \& Thompson, L. (2000). The challenge of learning. Negotiation Journal, 16, 399-408. doi:10.1023/ A:1026692922914

Mitgutsch, K. (2011). Serious learning in serious games: Learning in, through and beyond serious games. In M. $\mathrm{Ma}$, et al. (Eds.), Serious games and edutainment applications (pp. 45-58). London: Springer Science+Business Media.

Movius, H. (2008). The effectiveness of negotiation training. Negotiation Journal, 24, 509-531. doi:10.1111/j.15719979.2008.00201.x

Nadler, J., Thompson, L., \& Boven, L. V. (2003). Learning negotiation skills: Four models of knowledge creation and transfer. Management Science, 49, 529-540. doi:10.1287/mnsc.49.4.529.14431

Peng, W., Lee, M., \& Heeter, C. (2010). The effects of a serious game on role-taking and willingness to help. Journal of Communication, 60, 723-742. doi:10.1111/j.1460-2466.2010.01511.x

Raphael, C., Bachen, C. M., \& Hernández-Ramos, P. F. (2012). Flow and cooperative learning in civic game play. New Media \& Society, 14, 1321-1338. doi:10.1177/1461444812448744 
Schirmer, J. (1998). The Guatemalan military project: A violence called democracy. Philadelphia, PA: UPenn Press. Schori-Eyal, N., Halperin, E., \& Bar-Tal, D. (2014). Three layers of collective victimhood: Effects of multileveled victimhood on intergroup conflicts in the Israeli-Arab context. Journal of Applied Social Psychology, 44, 778-794. doi:10.1111/jasp.12268

Taber, C., \& Lodge, M. (2006). Motivated skepticism in the evaluation of political beliefs. American Journal of Political Science, 50, 755-769. doi:10.1111/j.1540-5907.2006.00214.x

Torney-Purta, J. (1998). Evaluating programs designed to teach international content and negotiation skills. International Negotiation, 3, 77-97. doi:10.1163/15718069820848111

Volkema, R. J. (2007). Negotiating for money: Adding a dose of reality to classroom negotiations. Negotiation Journal, 23, 473-485. doi:10.1111/j.1571-9979.2007.00159.x

Wilkenfeld, J., Young, K., Queen, D., \& Assal, V. (2005). Mediating international crises. Oxford, UK: Routledge. Yan, C. \& Cordry, J. (2011). Increased game immersion by using life player-mapped avatar evolution. In M. Chang, et al. (Eds.), Edutainment (pp. 276-280). Berlin, Germany: Springer-Verlag.

C. Esra Cuhadar is an assistant professor in the Department of Political Science and Public Administration at Bilkent University in Turkey. She was a Fulbright Visiting Scholar at Fletcher School of Law and Diplomacy at Tufts University during the 2011-2012 academic year. Dr. Cuhadar received her M.A. and Ph.D. and an advanced graduate certificate in Applied Conflict Resolution from Maxwell School of Citizenship and Public Affairs, Syracuse University. Dr. Cuhadar's research interests include mediation, interactive conflict resolution workshops, evaluation of peace building and conflict resolution programs, negotiation and mediation pedagogy, and political psychology with a focus on decision groups and political leaders.

Ronit Kampf received her Ph.D. in political communication from the Hebrew University of Jerusalem. She is a lecturer in the Department of Communication and the Program in Research of Child and Youth Culture at Tel Aviv University. She conducted her postdoctoral studies at the Center for the Study of Language and Information at Stanford University. Her research interests focus on serious games and learning, particularly in the context of the Israeli-Palestinian conflict. 